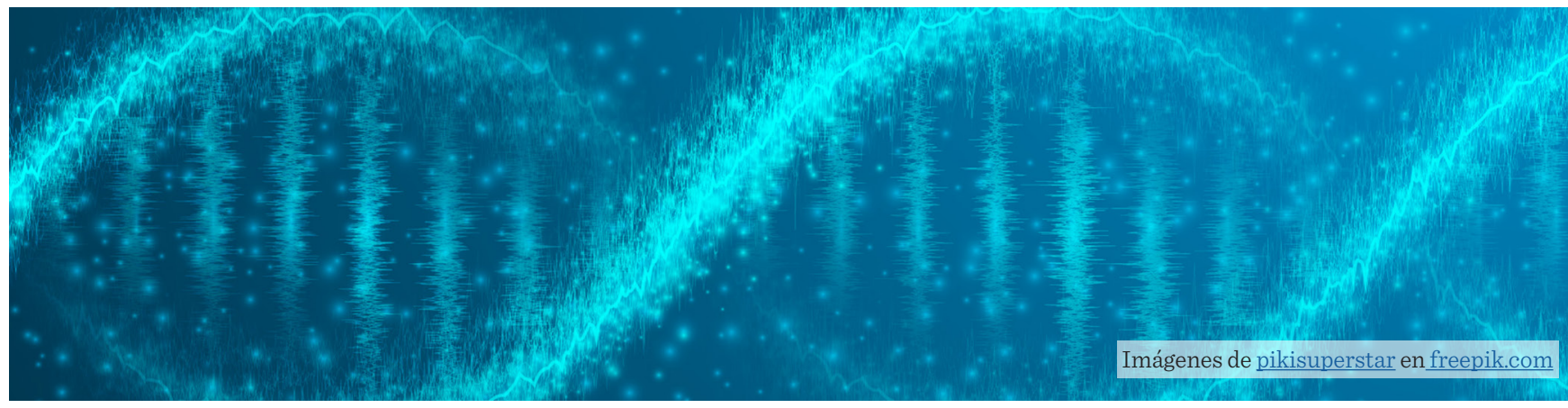

\title{
Metabarcoding de DNA ambiental: un enfoque para el seguimiento de la biodiversidad
}

\section{Environmental DNA metabarcoding: an approach for biodiversity monitoring}

\author{
Cinthia Yedith Padilla-García, Fátima Yedith Camacho-Sánchez, Miguel Ángel Reyes-López*
}

\section{RESUMEN}

El término ácido desoxirribonucleico ambiental o DNA ambiental (eDNA) se acuñó para definir al ácido desoxirribonucleico (DNA) que se puede recuperar o detectar del ambiente (por ejemplo: suelo, aire o agua) sin necesidad de que el espécimen esté físicamente presente. El objetivo del presente trabajo fue analizar y ejemplificar los usos, aplicaciones y potencial del eDNA. El estudio del eDNA es utilizado para la evaluación de especies, que va desde la reconstrucción histórica de sus comunidades, la restauración del ecosistema, hasta la salud humana, lo que lo convierte en una herramienta versátil e importante para el futuro en investigación, permitiendo estudios de conservación, taxonómicos o de reconstrucción filogenéticos. Para lograr esto, se usa el procedimiento de metabarcoding, el cual se basa en obtener DNA de cualquier origen (en este caso eDNA), en ausencia física o no del organismo, con apoyo de la reacción en cadena de la polimerasa (PCR), para finalmente, secuenciarlos y obtener códigos de barras. Los estudios de eDNA probablemente se constituirán como un enfoque esencial para diversas tareas científicas no solo en el seguimiento de la biodiversidad, sino en el análisis de la salud humana o la generación de códigos de barras de DNA.

PALABRAS CLAVE: eDNA, biodiversidad, PCR, secuenciación.

\section{ABSTRACT}

Environmental deoxyribonucleic acid or environmental DNA (eDNA) is a term coined to define the deoxyribonucleic acid (DNA) that can be recovered or detected in an environment (for example: soil, air, or water) sample, but not specimen physically present (metagenome). The objective of this review was to understand, analyze, and define the uses, applications, and potential of eDNA. eDNA brings together several fields ranging from ecological assessment for historical community reconstruction, ecosystem restoration to human health, making it extremely versatile and important for the future in research, such as studies of conservation, taxonomic, or phylogenetic reconstruction. To achieve this, the metabarcoding procedure is used, which is based on obtaining DNA of any origin (in this case eDNA), in the physical absence or not of organisms, with the polymerase chain reaction (PCR), to finally sequence them and develop barcodes. The application of eDNA in biological research seems almost limitless, but it requires collaboration and coordination of scientific teams. eDNA studies will probably become an essential tool for different scientific tasks not only in monitoring biodiversity, but also in human health analysis or in the development of DNA barcodes.

KEYWORDS: eDNA, biodiversity, PCR, sequencing.

*Correspondencia: mareyesl@gmail.com/ Fecha de recepción: 13 de diciembre de 2020/Fecha de aceptación: 25 de junio de 2021/Fecha de publicación: $2 \%$ de julio de 2021.

Instituto Politécnico Nacional, Centro de Biotecnología Genómica, Conservation Medicine Laboratory, boulevard del maestro s/n esquina Elías Piña, col. Narciso Mendoza, Reynosa, Tamaulipas México. C. P. 88710. 


\section{INTRODUCCIÓN}

El estudio y conocimiento de la diversidad genética, el cual detecta las variaciones heredables que pudieran ocurrir en cada organismo, entre los individuos de alguna población y entre poblaciones de una misma especie, cobra relevancia desde hace varias décadas por la diversidad de usos y trabajos que presenta. Para lograr implementar ese tipo de propuestas se requiere de una interrelación entre varias áreas, disciplinas o ciencias. Así, la genética y la evolución se agrupan para entender, describir y dar las pautas en trabajos de biodiversidad, para que sea estudiada o entendida y pueda ser protegida y conservada (Rimieri, 2017).

Alrededor del mundo se están perdiendo diversas especies (Scheffers y col., 2012; Raven, 2020) de flora y fauna silvestre debido a que el ser humano modifica los ambientes a través de la pérdida del hábitat, la contaminación ambiental (presencia de componentes nocivos en el medio ambiente, que pueden ser químicos, físicos o biológicos, ya sea en un entorno natural o artificial), la sobreexplotación, la introducción de especies invasoras, el cambio climático, entre otros (Koslowski y col., 2020). Además del empleo de algunos métodos convencionales (como quemas, generación de dióxido de carbono por industrias, incendios o combustión de automóviles, uso de plásticos, y otros) que aceleraron las alteraciones del ambiente y tal vez la pérdida de alguna especie, por lo que es necesario desarrollar metodologías más precisas que en algunos casos logren distinguir dos especímenes o especies entre sí, para finalmente detectarlos, diferenciarlos y contabilizarlos (Yildiz y col., 2019).

Aunque aún no existe la información completa de la magnitud de dicha pérdida de la biodiversidad, hay un acuerdo internacional llamado Plan Estratégico para la Biodiversidad 20112020, que marca los procedimientos para tratar de detener y revertir la pérdida de la biodiversidad de acuerdo al Programa de Naciones Unidas para el Medio Ambiente (UNEP, por sus siglas en inglés: United Nations Environment Programme) (UNEP, 2011). Estas ac- ciones dependen en gran medida del monitoreo biológico, que permite obtener datos de la especie, lo que se logra normalmente visualizándolas y cuantificándolas individuo por individuo basándose en diversos caracteres morfológicos. El dilema se presenta cuando las especies son similares o idénticas morfológica o anatómicamente (Thomsen y Willerslev, 2015; Deiner y col., 2017). Los errores que se presentan son muy comunes en la clasificación de algunos taxones debido a que se requiere personal altamente entrenado, por lo que se implementan otras técnicas para su identificación y futuro uso de la información (Bortolus, 2008; Hernández-González y col., 2016), como la caracterización molecular.

El campo de la biología molecular cobró relevancia desde el año 2000, dado que entre sus aplicaciones está el estudio de los genomas de organismos, desde un microorganismo hasta organismos superiores, como los humanos. Para entender cómo el estudio genómico de los ácidos nucleicos es utilizado en biodiversidad es necesario señalar que una molécula clave para esos estudios es el ácido desoxirribonucleico (DNA, por sus siglas en inglés: deoxyribonucleic acid), la cual está compuesta por átomos en forma de doble hélice y tiene cuatro bases nitrogenadas llamados nucleótidos: adenina, guanina, citosina y timina. El DNA se encarga de trasmitir la información genética (Vázquez-Ramos, 2016; Koch y col., 2020) y es útil para identificar individuos al comparar secuencias de origen distinto o no.

Con los estudios moleculares del DNA se puede complementar la morfología o la anatomía de especímenes o seres humanos, respectivamente, con lo se obtiene una mayor precisión de la identificación de sujetos (Pizarro, 2003), o mediante el uso de ácido ribonucleico (RNA, por sus siglas en inglés: ribonucleic acid), con el mismo principio de detección del DNA. Estos estudios requieren de cantidades pequeñas de muestra (micro o nanogramos) de ácido nucleico (DNA o RNA) usada para su análisis o amplificación; el protocolo es rápido (menos de 3 h) y está basado en la reacción en cade- 
na de la polimerasa (PCR, por sus siglas en inglés: polymerase chain reaction) (Zhu y col., 2020), o de un par de días para otras técnicas más elaboradas, comparadas con los cultivos de bacterias u hongos (de 1 d a 4 d o más días para hongos de lento crecimiento) (Austin, 2017); versátil (múltiple y/o diferentes tipos de muestras residuales) y, en algunos casos, barato (cuando se consideran pruebas masivas) (Deiner y col., 2017). Asimismo, es utilizada es la secuenciación (Mani, 2020), la cual cuenta con variantes, desde secuenciación química, enzimática, de electroforesis capilar, como la secuenciación tradicional, que por muchos años fue la más común, llamada secuenciación de Sanger, enzimática, capilar o de primera generación (Sanger y col., 1977; van-Dijk y col., 2018), que consume mucho tiempo, y se puede analizar especímen por especimen para obtener una secuencia a la vez. Ésta se basa en la terminación de la amplificación o extención de cadenas de ácidos nucleicos, lo cual produce cadenas de diferentes tamaños que se pueden agrupar por el nucleótido común en donde se terminó la reacción enzimática. Los avances en secuenciación pasaron de secuenciar unas cuantas muestras o fragmentos, hasta análisis de miles o millones de fragmentos en un solo ensayo por medio de secuenciación de siguiente generación (NGS, por sus siglas en inglés: next generation sequencing), por ejemplo. Esta técnica revolucionó las ciencias biológicas debido a su rendimiento masivo, escalabilidad y velocidad, lo que permite investigaciones en una amplia variedad de aplicaciones y estudios en sistemas biológicos a un nivel nunca antes posible (van-Dijk y col., 2018).

Por un lado, se tienen las secuencias de las especies o especímenes que se quiere identificar o estudiar y, por el otro, se debe saber si fueron o no identificados antes y si dicha secuencia ya está reportada. Con la información anterior, ambas secuencias son comparadas o alineadas. En el caso de que ya estén publicadas las secuencias se puede recurrir a sitios en la web que cuentan con herramientas bioinformáticas, como el GenBank (Benson y col., 2013), o mediante el uso de programas bioin- formáticos (ambas maneras se describen posteriormente).

Así, los análisis genómicos se basan en metodologías moleculares, las cuales muestran avances importantes en las técnicas de identificación de individuos o especímenes, lo que permiten detectarlos incluso sin tener evidencia física o visual del organismo (Andruszkiewicz y col., 2017b). Cabe señalar que estos estudios pueden dividirse en análisis con o sin amplificación de los ácidos nucleicos, llamados estudios de metabarcoding y metagenómicos, respectivamente.

En paralelo, las características de especies de vida silvestre u organismos que se cree extintos, escasos, escurridizos a simple vista o que no se pueden cultivar por métodos tradicionales, pueden inferirse mediante la detección de su DNA. A partir de este punto, el concepto de DNA ambiental (eDNA, por sus siglas en inglés: environmental DNA) emergió, describiéndose como el DNA que se puede obtener de muestras tomadas en el ambiente sin estar presente algún individuo físicamente (Taberlet $\mathrm{y}$ col., 2012; Ruppert y col., 2019), es decir, a partir de muestras de piel, pelo, fluidos u otros tejidos o materiales, como el suelo, aire o agua. Por lo que detectar el DNA y conocer a qué organismo o entidad biológica se parece es importante para obtener información sobre especies, poblaciones y comunidades (Thomsen y Willerslev, 2015) habitantes en un área específica o en determinado momento del tiempo.

Asegurar el éxito de la detección del eDNA dependerá de saber manejar la muestra recolectada y el posterior aislamiento e integridad del material genético obtenido de dicha muestra del medio ambiente (Andruszkiewicz y col., 2017a), hasta su identificación.

Este trabajo tuvo como objetivo dar a conocer el estado actual, usos y aplicaciones del estudio del eDNA, sus bondades, características, dificultades y aplicaciones en el estudio de la biodiversidad, salud, ambiente y de muestras antiguas. 


\section{I. eDNA}

El término eDNA fue introducido en 1980, utilizado para detectar y describir comunidades de microorganismos en sedimentos marinos (Ivanova y col., 2019). En 1990 fue clasificado de acuerdo al tamaño de la partícula: DNA mayor a $0.2 \mu \mathrm{m}$ fue descrito como DNA particulado, y menor a esto, DNA disuelto (Díaz-Ferguson y Moyer, 2014).

Para profundizar en el concepto: el DNA está contenido en materiales liberados por los organismos hacia el ambiente, los cuales pueden ser desde heces, mucosidades, células de la piel, organelos, gametos, inclusive, hasta DNA extracelular (Deiner y col., 2017). Como ya se demostró en diversos estudios, la técnica puede proporcionar información de macroorganismos extintos $u$ organismos que hace tiempo transitaron por un punto dado pero que ya no están en el área. Esto se debe a que los materiales orgánicos conservan cadenas cortas de DNA que se mantienen en el ambiente por largos espacios de tiempo (Ficetola y col., 2008).

Sin embargo, la obtención de este tipo de DNA no es fácil, ya que hay factores ambientales que pudieran afectarlo (Hänfling y col., 2016), como la temperatura, el $\mathrm{pH}$, la conductividad, o comunidades microbianas capaces de degradar el DNA (Andruszkiewicz y col., 2017a). Además, dependiendo del tipo de la muestra, como las heces, agua o sedimentos orgánicos, las concentraciones obtenidas en la extracción de DNA variarán, lo cual dependerá del espécimen, de su dieta, la estación del año, la densidad, que se encuentren en el agua o en el suelo, el tipo de sedimento (Valdez-Moreno y col., 2019), incluso de su pelaje. Los rangos de concentración de DNA que se puede obtener varían de $1 \mathrm{ng} / \mu \mathrm{L}$ a $10 \mathrm{ng} / \mu \mathrm{L}$ son suficientes para realizar un PCR de la muestra.

\section{Bases técnicas del uso del eDNA}

Para el estudio y análisis de eDNA se pueden seguir protocolos previamente publicados. En la metodología de Díaz-Ferguson y Moyer (2014) se argumenta que para la detección del eDNA se requiere el desarrollo de marcadores genéticos específicos para cada objetivo del trabajo. Los marcadores genéticos son secuencias conocidas dentro del ácido nucleico a estudiar y de las cuales se conoce normalmente su posición. Una vez detectados esos marcadores, se sintetizan sondas moleculares complementarias a ellos, para posteriormente ser empleados en diversos métodos, como el PCR, el cual amplifica millones de veces el fragmento de interés a estudiar, para enseguida ser visualizado a través de una electroforesis en geles de agarosa o poliacrilamida (Díaz-Ferguson y Moyer, 2014; Salipante y Jerome, 2020).

En algunas otras metodologías, como la que señalan Valdez-Moreno y col. (2019) y que se resume en la Figura 1, se utiliza el término metabarcoding, que implica la recolección de muestras ambientales (presencia física o no de los especímenes a estudiar), la extracción de DNA, amplificación por PCR para un gen de interés, por ejemplo, el gen mitocondrial de la citocromo oxidasa-I (COI por sus siglas en inglés: cytochrome c oxidase I) y secuenciación; también se puede emplear el procedimiento de "metagenómica", para la cual no requiere de la visualización física del espécimen del medio ambiente y que, además, implica una colección de genes amplificados y secuenciados (pero sin pasar por un PCR, a diferencia del metabarcoding, que sí lo requiere). Es decir, mientras la metagenómica analiza secuencias nucleares, cloroplastídicas o mitocondriales diversas sin el uso previo de PCR para secuenciar, el metabarcoding se basa en el mismo principio pero se apoya del PCR y utiliza secuencias conservadas, universales y con regiones variables, que pueden servir como código de barras.

Con lo anterior, se puede caracterizar la biodiversidad presente en una región dada, logrando la detección de especies o especímenes mediante la generación de sus secuencias específicas dentro del genoma o genoma mitocondrial del organismo, que servirán como una etiqueta molecular para la identificación de especies. Una serie de ejemplos de la versatilidad del estudio de eDNA se presenta como par- 


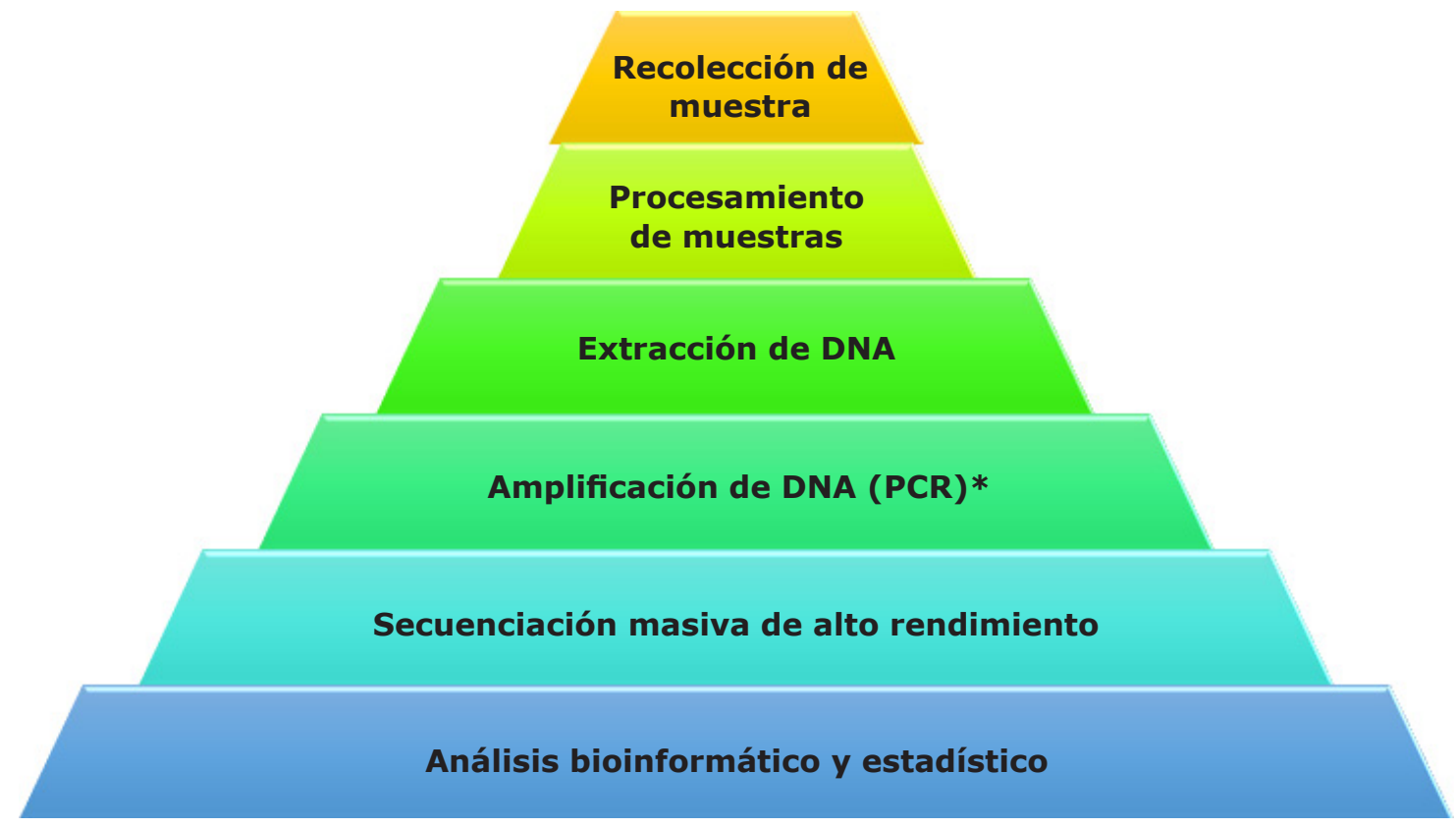

*Paso que puede o no ser omitido, dependiendo del tipo de análisis a realizar.

- Figura 1. Diagrama de flujo del procedimiento general para la obtención y análisis del eDNA (ValdezMoreno y col., 2019).

Figure 1. Flow chart for general procedure to extract and analyze eDNA (Valdez-Moreno y col., 2019).

te de la amplitud de este tipo de estudios. A modo de muestra, en el mar costero en Japón y en un río en Indiana, EE. UU., el DNA se aisló, se secuenció y se consiguió determinar, a partir de los restos de especímenes, el origen de una especie sin haber tenido conocimiento previo de su existencia en el lugar (Deiner y col., 2016; Lacoursière-Roussel y col., 2016; Valentini y col., 2016; Cowart y col., 2018; ValdezMoreno y col., 2019).

Otros ejemplos de los usos de eDNA son en la eutrofización (el proceso de contaminación más importante de las aguas en lagos, balsas, ríos, embalses, entre otros) de las cuerpos de agua, tanto dulce como de mar, la cual es causada por los efectos de las actividades humanas y los aportes de nutrientes, lo que podría provocar la proliferación de algas nocivas (HAB, por sus siglas en inglés: harmful algal blooms), disminución de la calidad del agua, reducción de la biodiversidad, lo cual podría amenazar la salud humana (Liu y col., 2020); con la técnica podría identificarse los organismos presentes, benéficos o no y sus implica- ciones en el ecosistema. Además, se podría estudiar el monitoreo de la biodiversidad, el eDNA podría usarse para estudios genéticos de poblaciones, lo cual es un campo emergente que ofrece perspectivas interesantes, sin embargo, habrá que seguir desarrollándolo (Adams y col., 2019).

Para obtener una muestra y su análisis como eDNA, a continuación se describen varios ejemplos donde se observa el uso de muestras de diferentes fuentes y orígenes, y su análisis.

\section{II.1. Recolección de muestra de agua}

Uno de los vehículos más comunes en el que se encuentra muestras de DNA o material con potencial DNA es el agua. De acuerdo a estudios realizados, donde se describe que la mayoría de los animales terrestres que se acercan a cuerpos de agua disponibles para beberla, tienen contacto de su saliva, tejido de su hocico o pelo y que éstos pueden caer y encontrarse en dicho fluido, es importante describir el procedimiento de cómo detectarlos. Por lo que se señala en general, el procedimiento marca que las muestras se tomen de 
la zona litoral a no más de $0.5 \mathrm{~m}$, para posteriormente almacenarse en botellas estériles, aunque la toma de la muestra se puede realizar directamente de agua dulce, salobre, subterránea y de cuerpos tanto lénticos como lóticos. Equipo y muestras deben ser manipulados utilizando guantes, para evitar contaminar (material con DNA o RNA de las personas que manejan la muestra, de bacterias del ambiente o de otras muestras cercanas) y colocarlas en hielo, para su posterior procesamiento. Todo el equipo de muestreo y filtrado se debe lavar con una solución de hipoclorito de sodio (llamada también lejía o cloro) comercial al $10 \%$ antes de su uso. Las muestras de agua tienen que ser recolectadas en envases de polietileno de aproximadamente $500 \mathrm{~mL}$. En paralelo, dos muestras testigos negativos (agua destilada) deben ser colectadas en los recipientes, para hacer el seguimiento de una potencial contaminación durante el muestreo y el transporte del agua (Ushio y col., 2017; ValdezMoreno y col., 2019). En México no se requieren permisos oficiales para la colecta de este tipo de muestras, ya que son del ambiente y no de vertebrados o de especies protegidas por las leyes mexicanas, pero en caso de que se produzca una perturbación en el sitio de muestreo o que se utilicen, aprovechen o descarguen aguas residuales sí se requeriría de un permiso oficial de acuerdo al Diario Oficial de la Federación (DOF, 2020) o lo procedente de acuerdo con las leyes y regulaciones del país o región de que se trate.

\section{II.2. Procesamiento de muestra de agua}

Las muestras de agua se deberán filtrar dentro de las $7 \mathrm{~h}$ de colectadas, para evitar que se degrade el material genético. Los artículos de filtrado más utilizados son los filtros de fibra de vidrio y los de nitrato de celulosa, con diferentes tamaños de poros. Los de poros más grandes permiten mayores volúmenes de agua y los de poros más pequeños capturan más partículas, pero limitan el volumen y la velocidad de filtración (Muha y col., 2019). Por ejemplo, existen filtros circulares de membrana de nitrato de celulosa Whatman, con tamaños de poros de $0.45 \mu \mathrm{m}$ y diámetro $47 \mathrm{~mm}$, y filtros de fibra de vidrio de borosilicato Advantec GA55 con tamaño de poros de $0.6 \mu \mathrm{m}$ y diámetro de $47 \mathrm{~mm}$. Ya en el laboratorio o lugar donde se procesará la muestra, se debe trabajar en un área estéril y tomar medidas para evitar la contaminación ambiental, por lo que habrá que cambiarse los guantes entre cada muestra o manejo de muestra, usar cubrebocas y, de ser posible, diferentes cuartos, tanto para la extracción del DNA como para la amplificación. Al terminar, el material filtrado se almacena a $-18{ }^{\circ} \mathrm{C}$ (Cowart y col., 2018; Valdez-Moreno y col., 2019).

\section{II.3. Extracción del DNA}

Para la extracción del DNA se pueden utilizar estuches comerciales (MoBio) normalmente vendidos como PowerSoil ${ }^{\circledR}$ DNA Isolation Kit Qiagen, especiales para muestras de suelo, con indicaciones del fabricante que deberán seguirse. Este método usa filtros, a diferencia de otros que no los requieren. El procedimiento no dura más de $10 \mathrm{~min}$. Posteriormente se debe incubar a $4{ }^{\circ} \mathrm{C}$ el DNA obtenido. Otros estuches comerciales (Muha y col., 2019) son DNA Qiagen DNeasy Blood \& Tissue (protocolo para manchas de sangre seca), usado para múltiples muestras, como tejido o sangre total. Uno más es Nexttec (Nexttec Biotechnologie GmbH, Alemania), con mayores ventajas debido a que evita una posible contaminación del DNA y que es de un solo paso entre la digestión (ruptura de paredes celulares y proteínas mediante enzimas o reactivos químicos) de la muestra y la elución final del DNA. También se puede usar el NucleoSpin ${ }^{\circledR}$ Soil (Soliman y col., 2017), el cual usa filtros y tiene una alta eficiencia en la obtención del DNA. Derivado de este último estudio, se recomienda para la estandarización el uso de diferentes individuos y por triplicado la extracción de DNA, lo que podría ser una solución para alcanzar un mejor protocolo para los estudios de metagenómica del suelo. Finalmente, se pueden usar procedimientos tradicionales para la extracción de DNA, como el de fenol: cloroformo (Green y Sambrook, 2017).

\section{II.4. Amplificación del DNA}

Para el estudio de las muestras de DNA exis- 
ten diferentes zonas blanco que habitualmente se usan como regiones (segmentos de DNA) de amplificación. Varios son los ejemplos: COI, para metazoos, y la cadena grande de bisfosfato de ribulosa carboxilasa (rcbL), para las plantas, son los estándares establecidos por el código de barras de la vida. Otras regiones usadas son el RNA ribosómico $12 \mathrm{~S}$ o el 16S, que pueden ser más apropiadas para diferentes taxones; para hongos se emplea ITS (por sus siglas en inglés: internal transcribed spacer) y en bacterias el 16S. Para ciertos eucariotas también se usa el 18S rRNA (Epp y col., 2012; Taberlet y col., 2012; Gibson y col., 2015; Creer y col., 2016; Deiner y col., 2017; Hering y col., 2018).

Los iniciadores para el metabarcoding de eDNA (Tabla 1) deben ser lo suficientemente cortos como para amplificar muestras degradadas, idénticas pero variables entre especies y flanqueadas por regiones altamente conservadas (segmentos de DNA que conservan su secuen- cia intacta a través del tiempo) para amplificar una variedad de especies sin sacrificar la especificidad del grupo objetivo. Se debe tomar en cuenta que se requieren procesos para asegurar que el producto amplificado sea real o verdadero y no falsos negativos, por lo que se realizan múltiples réplicas de PCR (realizar la reacción múltiples veces) y de réplicas biológicas (colectar más de una vez las mismas muestras biológicas).

Una metodología de amplificación que se usa con buenos resultados es realizar un PCR de dos pasos. En el primero se utilizan iniciadores convencionales y en el segundo, iniciadores de fusión con identificadores moleculares únicos (UMI, por sus siglas en inglés: unique molecular identifiers) o los códigos de barras moleculares (MBC, por sus siglas en inglés: molecular barcodes), que son secuencias de ácido nucleico cortas o "etiquetas" moleculares, útiles en los protocolos de preparación de bibliotecas de secuenciación de siguiente gene-

Tabla 1. Ejemplos de los 8 iniciadores más utilizados en el estudio de eDNA (Evans y col., 2016; Thomsen y col., 2016; Andruszkiewicz y col., 2017b; Bylemans y col., 2018; Wang y col., 2021). Table 1. Examples for the 8 commonly used primers in eDNA's study (Evans y col., 2016; Thomsen y col., 2016; Andruszkiewicz y col., 201\%b; Bylemans y col., 2018; Wang y col., 2021).

\begin{tabular}{|c|c|c|c|}
\hline Nombre iniciador & Sentido 5' a 3' & Secuencia & Amplicón (pb) \\
\hline \multirow{2}{*}{ FishCBa } & Directo & TCCTTTTGAGGCGCTACAGT & \multirow{2}{*}{130} \\
\hline & Reverso & GGAATGCGAAGAATCGTGTT & \\
\hline \multirow{2}{*}{$16 \mathrm{~S} 1 \mathrm{~b}$} & Directo & CGAGAAGACCCTWTGGAGCTTIAG & \multirow{2}{*}{107} \\
\hline & Reveso & GGTCGCCCCAACCRAAG & \\
\hline \multirow{2}{*}{ Ac16sc } & Directo & CCTTTTGCATCATGATTTAGC & \multirow{2}{*}{375} \\
\hline & Reverso & CAGGTGGCTGCTTTTAGGC & \\
\hline \multirow{2}{*}{$16 \mathrm{~S} 2 \mathrm{~d}$} & Directo & GACCCTATGGAGCTTTAGAC & \multirow{2}{*}{233} \\
\hline & Reverso & CGCTGTTATCCCTADRGTAACT & \\
\hline \multirow{2}{*}{ 16S-Fishe } & Directo & AGCGYAATCACTTGTCTYTTAA & \multirow{2}{*}{233} \\
\hline & Reverso & CRBGGTCGCCCCAACCRAA & \\
\hline \multirow{2}{*}{ Ac12sc } & Directo & ACTGGGATTAGATACCCCACTATG & \multirow{2}{*}{429} \\
\hline & Reverso & GAGAGTGACGGGCGGTGT & \\
\hline \multirow{2}{*}{ MiFish-Uf } & Directo & GTCGGTAAAACTCGTGCCAGC & \multirow{2}{*}{219} \\
\hline & Reverso & CATAGTGGGGTATCTAATCCCAGTTTG & \\
\hline \multirow{2}{*}{ Teleog } & Directo & ACACCGCCCGTCACTCT & \multirow{2}{*}{100} \\
\hline & Reverso & CTTCCGGTACACTTACCATG & \\
\hline
\end{tabular}

${ }^{*} \mathrm{~W}=\mathrm{A} \circ \mathrm{T} ; \mathrm{I}=$ inosina, $\mathrm{R}=\mathrm{A} \circ \mathrm{G}, \mathrm{D}=\mathrm{A}, \mathrm{G} \circ \mathrm{T} ; \mathrm{Y}=\mathrm{C} \circ \mathrm{T}, \mathrm{B}=\mathrm{C}, \mathrm{T} \circ \mathrm{G}$. 
ración. Después de la primera ronda, los productos de PCR se diluyen, para pasar a la segunda ronda de PCR. Finalmente, se purifica el DNA y se secuencia.

\section{II.5. Análisis Bioinformático}

Una vez obtenidas las secuencias, se comparan, resguardan y analizan. El primer paso pudiera ser subir las secuencias a una biblioteca mundial de secuencias. Existen diferentes bases de datos, una de las más conocidas es la del código de barras de la vida (BOLD, por sus siglas en inglés: barcode of life bata system). En ésta, cada secuencia cargada es clasificada y almacenada, para posteriormente ser comparada con secuencias ya existentes en el sistema. Una utilidad de lo anterior puede ser la clasificación de grupos de individuos relacionados, lo cual es conocido como unidad taxonómica operacional (OTU, por sus siglas en inglés: operational taxonomic unit), es decir, las secuencias son agrupadas por similitud de secuencias de DNA de un gen marcador taxonómico específico. Otra base de datos es la que se encuentra en el GenBank, que indica estar diseñada para proporcionar y fomentar el acceso de la comunidad científica a la información de las secuencias de DNA más actualizadas y completas, y forma parte de lo que es el sitio web de El Centro Nacional de Información Biotecnológica (NCBI, por sus siglas en inglés: National Center for Biotechnology Information), que promueve la ciencia y la salud al proporcionar acceso a información biomédica y genómica. Ello ayudará a determinar si la secuencia problema secuenciada existe o no en dicha base de datos, si es una secuencia conocida, o es la primera vez que se detecta.

Por otro lado, derivado de la generación de cientos, miles o millones de secuencias por análisis, fueron creados sitios web para reunir tal información, como es el caso de mBRAVE (multiplex barcode research and visualization environment), una plataforma multiusuario que admite el almacenamiento, la validación, el análisis y la publicación de numerosos proyectos basados en instrumentos de secuenciación de alto rendimiento (HTS, por sus siglas en inglés: high-throughput sequencing). Este sistema se basa en la plataforma BOLD para respaldar la identificación y el descubrimiento de especies para los datos de HTS (Ratnasingham, 2019).

El procesamiento y la subida de los datos a ese tipo de plataforma de almacenamiento se pueden llevar a cabo por medio de diferentes paquetes informáticos. Entre otros, QIIME2 (por sus siglas en inglés: quantitative insights into microbial ecology version 2), DADA2 (por sus siglas en inglés: the divisive amplicon denoising algorithm) u OBITools, que es un conjunto de programas de Python (lenguaje bioinformático) desarrollados para simplificar la manipulación de archivos de secuencias (Boyer y col., 2016; Callahan y col., 2016; Macher y col., 2021).

QIIME2 puede transformar secuencias sin procesar en diagramas de barras taxonómicas, árboles filogenéticos, análisis de coordenadas principales y otras visualizaciones de la diversidad microbiana. Para DADA2 se incluyen herramientas o procedimientos sobre cómo filtrar tablas y cómo calcular y visualizar los análisis de ordenamiento y medición de la diversidad, para lo cual se introdujo un enfoque basado en modelos para corregir errores del amplicón sin construir OTU. Así, DADA2 es precedido de otro paquete informático basado en el programa de R, el cual es de código abierto (https:/github.com/benjjneb/dada2) que extiende y mejora el algoritmo de su predecesor. Mientras que OBITools hace la asignación taxonómica de secuencias automáticamente contra una base de datos en línea. Tiene capacidad para filtrar y editar secuencias teniendo en cuenta la anotación taxonómica y ayuda a establecer líneas de análisis a medida para una amplia gama de aplicaciones de metabarcoding de DNA, incluidos estudios de biodiversidad o análisis de dietas.

\section{III. eDNA en agua}

\section{III.1. eDNA en acuíferos}

El método para obtener eDNA de acuíferos se efectuó primeramente en ambientes controlados, para observar si era viable la detección 
de especies, para posteriormente ser aplicado a ambientes naturales (Ficetola y col., 2008). El eDNA es, relativamente, una nueva herramienta para el monitoreo que se utiliza en ambientes acuíferos, ya que las partículas de DNA se distribuyen homogéneamente en el agua, a comparación del DNA que pudiera encontrarse en el suelo (Hänfling y col., 2016). La mayoría de los estudios sobre este tema se enfocan en peces y anfibios, pero esta herramienta se diversificó tanto que también se usa para identificar mamíferos, reptiles, artrópodos, gasterópodos y bivalvos (Dougherty y col., 2016).

La técnica del eDNA mostró su utilidad al ser empleada por primera vez para el monitoreo de peces que habitan la región de Bacalar (México) y a la vez detectar especies invasoras que pudieran afectar las playas. Se aplicó en agua y sedimentos, descubriendo que era más viable en agua, ya que fue capaz de localizar un mayor número de organismos (Valdez-Moreno y col., 2019). En este estudio se incluyeron 8 sitios de muestreo (1 con 3 localidades), la mayoría fueron examinadas en más de una ocasión, produciendo un total de 14 eventos de muestreo. Las muestras fueron colocadas en botellas, y tanto éstas como el equipo de muestreo se manipularon con guantes, para minimizar la contaminación con DNA humano. En cada sitio se hicieron tres tomas repetidas de agua y sedimento. Cada muestra se dividió en dos submuestras de $0.5 \mathrm{~L}$ que se filtraron a través de filtros separados de $0.22 \mu \mathrm{m}$. Un filtro se almacenó con $1 \mathrm{~mL}$ de solución PW1 (solución encontrada en el estuche comercial DNeasy ${ }^{\circledR}$ PowerWater ${ }^{\circledR}$ Kit - QIAGEN) con medio de trituración (cuentas que ayudan al molido de la muestra), mientras que la otra submuestra se colocó con medio de trituración en un tubo seco cubierto con papel de aluminio.

\section{III.2. eDNA en ríos}

Los ríos son invaluables para los estudios ambientales, ya que transportan la información genética del paisaje a lo largo de los tramos que atraviesan, así como los sedimentos, material orgánico y los nutrientes a su alrededor (Deiner y col., 2016). El eDNA es empleado pa- ra el conteo e identificación de poblaciones de peces, principalmente, mediante métodos no invasivos, en contraste con los invasivos usados anteriormente para esto, donde eran capturados e identificados morfológicamente, lo que no ayuda mucho a la salud del animal, ya que le provoca estrés y aumenta su depredación (Shaw y col., 2016).

El eDNA resiste en el agua a temperatura ambiente y puede cambiar su integridad de unos días a algunas semanas, de acuerdo a un trabajo de Pont y col. (2018), que reveló patrones cuantitativos de la biodiversidad de peces. También señaló que en las corrientes de los ríos la concentración de eDNA y su detectabilidad no solo dependen de las tasas de producción y degradación, sino también de la dilución, el transporte a través de la red fluvial, la deposición y la resuspensión. Este estudio usó como referencia uno previo de Valentini y col. (2016), el cual diseñó iniciadores que se probaron exhaustivamente in silico utilizando el programa ecoPCR (Ficetola y col., 2010) en: (i) una colección de todas las secuencias de DNA mitocondrial y (ii) en todas las secuencias de DNA disponibles públicamente. El programa ecoPCR es un PCR in silico que consiste en seleccionar en una base de datos las regiones que coinciden (es decir, que presentan similitud) con dos iniciadores de PCR. Dichas regiones deben localizarse en la secuencia seleccionada, de manera que permitan la amplificación por PCR, lo que fuerza la orientación relativa de las coincidencias y la distancia entre ellas.

Deiner y col. (2016), mostraron que el método de eDNA ayudó a detectar más especies en comparación con un método convencional llamado "kicknet" (que utiliza una red de malla cuadrada con un mango de poste a cada lado que se emplea para recoger macroinvertebrados acuáticos en una corriente). Utilizando solo kicknet se consiguieron de 17 a 24 familias, y combinándolo con eDNA se obtuvieron de 23 a 40 familias (Deiner y col., 2016; 2017). Existen otros trabajos reportados en Indiana, EE. UU., donde el método combinado ayudó a 
identificar especies que otros métodos pasaron por alto, en comparación con el método convencional (kicknet). Deiner y col. (2016; 2017) identificaron un promedio de 12 especies, entre las que se encontraron Semotilus atromaculatus, Lepomis cyanellus, Etheostoma nigrum, Cottus bairdii, Rhinichthys obtusus, Catostomus commersonii, Oncorhynchus mykiss, Salmo trutta, Amblopites rupestris, Micropterus dolomieu, Lepomis macrochinus, y Etheostoma caeruleum; y con kicknet y eDNA se obtuvieron 4 especies más; Ameiurus natalis, Cyprinus carpio, Umbra pygmaea y Micropterus salmoides, dando un promedio de 16 especies en 2013 (Olds y col., 2016; Valdez-Moreno y col., 2019). Finalmente, otro estudio en Japón usando eDNA, descubrió especies acuáticas raras, en peligro de extinción, y especies invasoras (Yamamoto y col., 2017).

\section{IV. eDNA en ambientes terrestres}

Los sedimentos son una fuente muy valiosa para el estudio de eDNA, el DNA puede permanecer desde periodos cortos hasta miles de años, dependiendo de las condiciones del ambiente donde se encuentre la muestra (Buxton y col., 2018). Algunos estudios demuestran que el eDNA se mantiene más tiempo en el sedimento que en la superficie del agua. Turner y col. (2015) demostraron que el DNA de la carpa asiática de cabeza grande se conserva por 4 meses en el sedimentos y está más concentrado que en las columnas de agua (Turner y col., 2015).

Así como en el agua, los sedimentos terrestres son muy importantes, ya que ayudan a investigar y reconstruir evidencias de animales o comunidades de plantas que habitaron la tierra hace miles de años (Deiner y col., 2017). Es decir, la fauna y la flora ancestrales dejaron ahí rastros de DNA extracelular. En 2013, otro trabajo estudió sedimentos en Siberia y en Nueva Zelanda, descubriendo que contenían DNA de animales extintos, como el mamut lanudo, en el primer sitio, y las aves de Moa en el segundo (Pedersen y col., 2015). Para lograr el metabarcoding se utilizaron iniciadores genéricos (o universales), que están diseñados pa- ra apuntar a varios taxones simultáneamente, entre ellos, plantas, animales o muestras fecales, en contraste con los iniciadores específicos, diseñados para amplificar sólo unas pocas especies seleccionadas. Por esta razón y derivado, que con la tecnología molecular podía detectarse DNA, los investigadores le llamaron DNA ancestral o "antiguo" (aDNA, por sus siglas en inglés: ancient DNA).

Aunque parece "fácil" la detección del aDNA, se debe considerar que su campo está plagado de obstáculos metodológicos significativos que incluyen, entre otros, daño post mortem a biomoléculas conservadas, contaminación de muestras y reactivos por DNA moderno y la presencia de inhibidores de reacciones enzimáticas (McHugo y col., 2019). En general, diversos factores que pueden comprometer irrevocablemente la autenticidad y reproducibilidad de un DNA amplificado a partir de muestras arqueológicas o fortuitas encontradas en zonas donde posiblemente habitaron animales o plantas prehistóricas. Sin embargo, con los cuidados de muestreo, transportación, enriquecimiento del DNA en el momento de su extracción y, claro, la tecnología de la amplificación, se tiene el potencial para estudios de detección de flora y fauna ancestral.

\section{V. eDNA en el aire}

El agua y el aire son capaces de desplazar el DNA ambiental más rápido y a mayores distancias (Barnes y Turner, 2016). Específicamente, el aire es un medio importante de transporte de microorganismos ya que supera barreras geográficas (Yooseph y col., 2013) y traslada diferentes partículas de material diverso, polvo, microorganismos, esporas, polen, entre otros.

Por ello, el eDNA puede tener aplicaciones en la salud humana utilizando como muestra el aire ambiental de alguna zona o ecosistema dado. Determinar el microbioma en el aire puede influir en las decisiones de salud con respecto a los alérgenos (partícula o microorganismos que genera una reacción inmunológica de hipersensibilidad), los microorganismos pa- 
tógenos y la contaminación del aire. Así se debe considerar, por ejemplo, la actual pandemia del síndrome respiratorio agudo grave (SARS, por sus siglas en inglés: severe acute respiratory syndrome), la cual es una enfermedad respiratoria viral causada por un coronavirus del tipo 2, llamado coronavirus asociado al SARS (SARS-CoV-2) que provoca la enfermedad conocida como COVID-19 (Wang y col., 2020). Para el caso de los microorganismos en aire, la identificación actualmente se realiza mediante la observación microscópica, la cual se torna laboriosa y en muchos casos no se logran reconocer, a nivel de género, todas las especies relevantes (Kraaijeveld y col., 2015) o cultivables, para su posterior identificación. Mediante la recolección de muestras del aire, aplicación del metabarcoding y la tecnología NGS es posible determinar la composición del microbioma en el aire y sus posibles implicaciones para la salud humana y el ecosistema.

Si bien, el uso más frecuente de metabarcoding ambiental es en entornos naturales, también se puede aplicar en interiores. En particular, los microorganismos transportados por el aire son una preocupación crítica en los espacios de atención a la salud, ya que algunos pueden causar infecciones asociadas a los hospitales $\mathrm{y}$, en general, a lugares donde se tienen en uso equipos de aire acondicionado que pueden contener bacterias, virus u hongos (Cao y col., 2014; Banchi y col., 2018).

Un ejemplo de la aplicación de esta metodología fue en 2015 , cuando se realizó un estudio en aguas marinas para la identificación de orcas (Orcinus orca); para ello se tomaron muestras de agua y aire/superficie de las Islas de San Juan. Del aire/superficie se obtuvo la muestra de DNA por medio de filtros. El análisis de las muestras de las superficie encontró excelente concentración de DNA y se logró secuenciar a los microorganismos (Baker y col., 2018). Para este estudio, además del eDNA, se utilizó una variante del PCR llamado PCR por gotitas digitales (ddPCR, por sus siglas en inglés: droplet-digital PCR), la cual es una nueva y poderosa tecnología para cuantificar niveles ba- jos de DNA mediante el fraccionamiento de una reacción de PCR en más de 20000 gotas utilizando una emulsión de aceite (Doi y col., 2015).

En otro caso, se comprobó que se puede identificar el polen de las plantas que potencialmente es alérgeno. Lo que se hizo fue filtrar las muestras de aire (Kraaijeveld y col., 2015) para localizar el tipo de polen.

En realidad, la utilidad del metabarcoding de eDNA se vuelve infinita, en virtud de que es posible hacer un procedimiento de análisis relativamente sencillo, aislando un fluido (aire o agua) de uno o de diferentes entornos, y después determinando uno o varios organismos, con el examen del microbioma de un ambiente específico; en muchos casos, sin necesidad de crecimiento o siembra de tales microorganismos.

\section{CONCLUSIONES}

El avance de la ciencia conlleva a nuevos descubrimientos, técnicas y metodologías producto del trabajo de investigación, dedicación y tiempo. En biología molecular abarca nuevas maneras de analizar lo que antes era casi imposible, debido a que no se podían identificar simultáneamente a todos o una parte de los organismos de un ambiente dado. La reciente introducción de la técnica metabarcoding de ácido desoxirribonucleico (DNA) y en particular del estudio de DNA ambiental (eDNA) ha permitido alcanzar ese objetivo. Actualmente existe información disponible sobre el metabarcoding y eDNA, en particular, en agua, lo cual es muy relevante para la detección de especies nuevas, previamente descritas o especies invasoras para el ecosistema, los humanos, los animales o las plantas. Sin embargo, aún faltan más estudios en otros tipos de muestras, como suelos y aire. Se espera que en un futuro esta sea la manera para la caracterización y clasificación de especies y que su uso se generalice para el monitoreo de microorganismos, especies terrestres o acuáticas que se encuentran en números muy bajos, se cree que ya están extintas o son especies nuevas. Es importante destacar que se requiere de técnicas 
especiales, como la reacción en cadena de la polimerasa (PCR) y secuenciación de terminación de la cadena de Sanger o de siguiente generación. En esta primera etapa es necesario generar las bases de datos de todo tipo de especímenes, por ejemplo, de cuerpos de fluidos, para que existan referencias con qué compararse o en su defecto, si ya existen, comparar las secuencias obtenidas con esas bases de datos previamente creadas. Finalmente, con el metabarcoding se generará un código de barras para algún tipo de muestra que se desee estudiar y con esto lograr el inventario de la biodiversidad de un área en particular y por qué no, el inventario total de la Tierra, entre otras aplicaciones mencionadas en este trabajo.

\section{REFERENCIAS}

Adams, C. I., Knapp, M., Gemmell, N. J., Jeunen, G. J., Bunce, M., Lamare, M. D., and Taylor, H. R. (2019). Beyond Biodiversity: Can Environmental DNA (eDNA) Cut It as a Population Genetics Tool? Genes. 10(3): 192.

Andruszkiewicz, E. A., Sassoubre, L. M., and Boehm, A. B. (2017a). Persistence of marine fish environmental DNA and the influence of sunlight. PLoS One.12(9).

Andruszkiewicz, E. A., Starks, H. A., Chavez, F. P., Sassoubre, L. M., Block, B. A., and Boehm, A. B. (2017b). Biomonitoring of marine vertebrates in Monterey Bay using eDNA metabarcoding. PLoS One. 12(4): e0176343.

Austin, B. (2017). The value of cultures to modern microbiology. Antonie Van Leeuwenhoek. 110(10): 1247-1256. Banchi, E., Ametrano, C. G., Stanković, D., Verardo, P., Moretti, O., Gabrielli, F., ..., and Muggia, L. (2018). DNA metabarcoding uncovers fungal diversity of mixed airborne samples in Italy. PLoS One. 13: e0194489.

Baker, C. S., Steel, D., Nieukirk, S., and Klinck, H. (2018). Environmental DNA (eDNA) from the wake of the whales: Droplet digital PCR for detection and species identification. Frontiers in Marine Science. 5: 1-11.

Barnes, M. A. and Turner, C. R. (2016). The ecology of environmental DNA and implications for conservation genetics. Conservation Genetics. 17(1): 1-17.

Benson, D. A., Cavanaugh, M., Clark, K., Karsch-Mizrachi, I., Lipman, D. J., Ostell, J., and Sayers, E. W. (2013). GenBank. Nucleic Acids Research. 41(D1): D36-D42.

Bortolus, A. (2008). Error cascades in the biological sciences: The unwanted consequences of using bad taxonomy in ecology. AMBIO: A Journal of the Human Environment. 37(2): 114-118.

Boyer, F., Mercier, C., Bonin, A., Le-Bras, Y., Taberlet, P., and Coissac, E. (2016). Obitools: a unix-inspired software package for DNA metabarcoding. Molecular Ecology Resources. 16(1): 176-182.

Buxton, A. S., Groombridge, J. J., and Griffiths, R. A. (2018). Seasonal variation in environmental DNA detection in sediment and water samples. PLoS One.13(1):1-14.

Bylemans, J., Gleeson, D. M., Hardy, C. M., and Furlan, E.
(2018). Toward an ecoregion scale evaluation of eDNA metabarcoding primers: A case study for the freshwater fish biodiversity of the Murray-Darling Basin (Australia). Ecology and Evolution. 8(17): 8697-8712.

Callahan, B. J., McMurdie, P. J., Rosen, M. J., Han, A. W., Johnson, A. J., and Holmes, S. P. (2016). DADA2: High-resolution sample inference from Illumina amplicon data. Nature Methods. 13(7): 581-583.

Cao, C., Jiang, W., Wang, B., Fang, J., Lang, J., Tian, G., ..., and Zhu, T. F. (2014). Inhalable microorganisms in Beijing's PM2.5 and PM10 pollutants during a severe smog event. Environmental Science \& Technology. 48(3): 1499-1507.

Cowart, D. A., Murphy, K. R., and Cheng, C. H. C. (2018). Metagenomic sequencing of environmental DNA reveals marine faunal assemblages from the West Antarctic Peninsula. $M a-$ rine Genomics. 37: 148-160.

Creer, S., Deiner, K., Frey, S., Porazinska, D., Taberlet, P., Thomas, W., ..., and Bik, H. (2016). The ecologist's field guide to sequence-based identification of biodiversity. Methods in Ecology and Evolution. 7(9): 1008-1018.

Deiner, K., Bik, H. M., Mächler, E., Seymour, M., LacoursièreRoussel, A., Altermatt, F., ..., and Bernatchez, L. (2017). Environmental DNA metabarcoding: Transforming how we survey animal and plant communities. Molecular Ecology. 26(21): 58725895.

Deiner, K., Fronhofer, E. A., Mächler, E., Walser, J. C., and Altermatt, F. (2016). Environmental DNA reveals that rivers are conveyer belts of biodiversity information. Nature Communications. 7(1): 1-9.

Díaz-Ferguson, E. E. and Moyer, G. R. (2014). History, applications, methodological issues and perspectives for the use environmental DNA (eDNA) in marine and freshwater environments. Revista de Biología Tropical. 62(4): 1273-1284.

DOF, Diario Oficial de la Federación (2020). Ley de Aguas Nacionales. [En línea]. Disponible en: http://www.diputados.gob. mx/LeyesBiblio/pdf/16_060120.pdf. Fecha de consulta: 10 de junio de 2021. 
Doi, H., Uchii, K., Takahara, T., Matsuhashi, S., Yamanaka, H., and Minamoto, T. (2015). Use of droplet digital PCR for estimation of fish abundance and biomass in environmental DNA surveys. PLoS One.10(3): e0122763.

Dougherty, M. M., Larson, E. R., Renshaw, M. A., Gantz, C. A., Egan, S. P., Erickson, D. M., and Lodge, D. M. (2016). Environmental DNA (eDNA) detects the invasive rusty crayfish Orconectes rusticus at low abundances. Journal of Applied Ecology. 53(3): 722-732.

Epp, L. S., Boessenkool, S., Bellemain, E. P., Haile, J., Esposito, A., Riaz, T., ..., and Brochmann, C. (2012). New environmental metabarcodes for analysing soil DNA: potential for studying past and present ecosystems. Molecular Ecology. 21: 1821-1833.

Evans, N. T., Olds, B. P., Renshaw, M. A., Turner, C. R., Li, Y., Jerde, C. L., ..., and Lodge, D. M. (2016). Quantification of mesocosm fish and amphibian species diversity via environmental DNA metabarcoding. Molecular Ecology Resources. 16(1): 29-41.

Ficetola, G. F., Coissac, E., Zundel, S., Riaz, T., Shehzad, W., Bessière, J., ..., and Pompanon, F. (2010). An in silico approach for the evaluation of DNA barcodes. BMC Genomics: 11(1): 434.

Ficetola, G. F., Miaud, C., Pompanon, F., and Taberlet, P. (2008). Species detection using environmental DNA from water samples. Biology Letters. 4(4): 423-425.

Gibson, J. F., Shokralla, S, Curry, C., Baird, D. J., Monk, W. A., King, I., and Hajibabaei, M. (2015). Large-Scale Biomonitoring of Remote and Threatened Ecosystems via High-Throughput Sequencing. PLoS One.10(10): e0138432.

Green, M. R. and Sambrook, J. (2017). Isolation of High-Molecular-Weight DNA Using Organic Solvents. Cold Spring Harb Protoc. (4): pdb.prot093450.

Hänfling, B., Handley, L. L., Read, D. S., Hahn, C., Li, J., Nichols, P., ..., and Winfield, I. J. (2016). Environmental DNA metabarcoding of lake fish communities reflects long-term data from established survey methods. Molecular Ecology. 25(13): 3101-3119.

Hering, D., Borja, A., Jones, J. I., Pont, D., Boets, P., Bouchez, A., ..., and Kelly, M. (2018). Implementation options for DNA-based identification into ecological status assessment under the European Water Framework Directive. Water Research. 138: 192-205.

Hernández-González, J., Inza, I., and Lozano, J. A. (2016). Weak supervision and other non-standard classification problems: A taxonomy. Pattern Recognition Letters. 69: 49-55.

Ivanova, N., Valdez-Moreno, M., and Elias-Gutierrez, M. (2019). Resident or Invasive Species? Environmental DNA Can Provide Reliable Answers. IBOL Barcode Bulletin. 9(1): 9-11.

Kraaijeveld, K., de-Weger, L. A., Ventayol-García, M., Buermans, H., Frank, J., Hiemstra, P. S., and den-Dunnen, J. T. (2015). Efficient and sensitive identification and quantification of air- borne pollen using next-generation DNA sequencing. Molecular Ecology Resources. 15(1): 8-16.

Koch, J., Gantenbein, S., Masania, K. Stark, W. J., Erlich, Y., and Grass, R. N. (2020). A DNA-of-things storage architecture to create materials with embedded memory. Nature Biotechnology. 38(1): 39-43.

Koslowski, M., Moran, D., Tisserant, A., Verones, F., and Wood, R. (2020). Quantifying Europe's biodiversity foot-prints and the role of urbanization and income. Global Sustainability. 3: E1.

Lacoursière-Roussel, A., Dubois, Y., Normandeau, E., and Bernatchez, L. (2016). Improving herpetological surveys in eastern North America using the environmental DNA method1. Genome. 59(11): 991-1007.

Liu, Q., Zhang, Y., Wu, H., Liu, F., Peng, W., Zhang, X., ..., and Zhang, H. (2020). A Review and Perspective of eDNA Application to Eutrophication and HAB Control in Fresh-water and Marine Ecosystems. Microorganisms. 8(3): 41\%.

Macher, T. H., Beermann, A. J., and Leese, F. (2021). Taxon TableTools: A comprehensive, platform-independent graphical user interface software to explore and visualise DNA metabarcoding data. Molecular Ecology Resources. 21(5): 1705-1714.

Mani, I. (2020). Current Status and Challenges of DNA Sequencing. In V. Singh (Ed.), Advances in Synthetic Biology (pp. 71-80). Alemania: Springer, Singapore.

McHugo, G. P., Dover, M. J., and MacHugh, D. E. (2019). Unlocking the origins and biology of domestic animals using ancient DNA and paleogenomics. BMC Biology. 17(1): 1-20.

Muha, T. P., Robinson, C. V., Garcia-de-Leaniz, C., and Consuegra, S. (2019). An optimised eDNA protocol for detecting fish in lentic and lotic freshwaters using a small water volume. PLoS One. 14(7): e0219218.

Olds, B. P., Jerde, C. L., Renshaw, M. A., Li, Y., Evans, N. T., Turner, C. R., ..., and Lamberti, G. A. (2016). Estimating species richness using environmental DNA. Ecology and Evolution. 6(12): 4214-4226.

Pedersen, M. W., Overballe-Petersen, S., Ermini, L., DerSarkissian, C., Haile, J., Hellstrom, M., ..., and Willerslev, E. (2015). Ancient and modern environmental DNA. Philosophical Transactions of the Royal Society B: Biological Sciences. 370(1660): 20130383.

Pizarro, O. R. (2003). Proyecto de ley para un registro de ADN de utilización Criminalística. Revista Conamed. 8(2): 21-34.

Pont, D., Rocle, M., Valentini, A., Civade, R., Jean, P., Maire, A., ..., and Dejean, T. (2018). Environmental DNA reveals quantitative patterns of fish biodiversity in large rivers despite its downstream transportation. Scientific Reports. 8(1):1-13.

Ratnasingham, S. (2019). mBRAVE: The Multiplex Barcode Research And Visualization Environment. Biodiversity Information Science and Standards. 3. 
Raven, P. H. (2020) Biodiversity: A Global Perspective. In G. Dar and A. Khuroo (Eds.), Biodiversity of the Himalaya: Jammu and Kashmir State. Topics in Biodiversity and Conservation (pp. 156-180). Alemania: Springer, Singapore.

Rimieri, P. (2017). Genetic Diversity and Genetic Variability: Two Different Concepts Associated To Plant Germplasm and Breeding. Journal of Basic and Applied Genetics. 28(2): 7-13.

Ruppert, K. M., Kline, R. J., and Rahman, M. S. (2019). Past, present, and future perspectives of environmental DNA (eDNA) metabarcoding: A systematic review in methods, monitoring, and applications of global eDNA. Global Ecology and Conservation. 17: e00547.

Salipante, S. J. and Jerome, K. R. (2020). Digital PCR-An Emerging Technology with Broad Applications in Microbiology. Clinical Chemistry.66(1): 117-123.

Sanger, F., Nicklen, S., and Coulson, A. R. (1977). DNA sequencing with chain-terminating inhibitors. Proceedings of the $\mathrm{Na}$ tional Academy of Sciences of the United States of America. 74(12): 5463-7.

Scheffers, B., Joppa, L., Pimm, S., and Laurance, W. (2012). What we know and don't know about Earth's missing biodiversity. Trends in Ecology \& Evolution. 27(9): 501-10.

Shaw, J. L. A., Clarke, L. J., Wedderburn, S. D., Barnes, T. C., Weyrich, L. S., and Cooper, A. (2016). Comparison of environmental DNA metabarcoding and conventional fish survey methods in a river system. Biological Conservation. 197: 131-138.

Soliman, T., Yang, S. Y., Yamazaki, T., and Jenke-Kodama, H. (2017). Profiling soil microbial communities with next-generation sequencing: the influence of DNA kit selection and technician technical expertise. PeerJ. 5: e4178.

Taberlet, P., Coissac, E., Hajibabaei, M., and Rieseberg, L. H. (2012). Environmental DNA. Molecular Ecology. 21(8): 1789-1793.

Thomsen, P. F., Møller, P. R., Sigsgaard, E. E., Knudsen, S. W., Jørgensen, O. A., and Willerslev, E. (2016). Environmental DNA from Seawater Samples Correlate with Trawl Catches of Subarctic, Deepwater Fishes. PLoS One. 11(11): e0165252.

Thomsen, P. F. and Willerslev, E. (2015). Environmental DNA - An emerging tool in conservation for monitoring past and present biodiversity. Biological Conservation. 183: 4-18.

Turner, C. R., Uy, K. L., and Everhart, R. C. (2015). Fish environmental DNA is more concentrated in aquatic sediments than surface water. Biological Conservation. 183: 93-102.

UNEP, United Nations Environment Programme (2011). Convention of Biological Diversity: Strategic Plan for Biodiveristy 2011-2020. [En línea]. Disponible en: https://www.cbd.int/doc/ strategic-plan/2011-2020/Aichi-Targets-EN.pdf. Fecha de consulta: 21 de enero de 2021.

Ushio, M., Fukuda, H., Inoue, T., Makoto, K., Kishida, O., Sato, K., ..., and Miya, M. (2017). Environmental DNA enables detec- tion of terrestrial mammals from forest pond water. Molecular Ecology Resources. 17(6): e63-er75.

Valdez-Moreno, M., Ivanova, N. V., Elías-Gutiérrez, M., Pedersen, S. L., Bessonov, K., and Hebert, P. D. (2019). Using eDNA to biomonitor the fish community in a tropical oligotrophic lake. PLoS One. 14(4): 1-22.

Valentini, A., Taberlet, P., Miaud, C., Civade, R., Herder, J., Thomsen, P. F., ..., and Dejean, T. (2016). Next-generation monitoring of aquatic biodiversity using environmental DNA metabarcoding. Molecular Ecology. 25(4): 929-942.

van-Dijk, E. L, Jaszczyszyn, Y., Naquin, D., and Thermes, C. (2018). The Third Revolution in Sequencing Technology. Trends in Genetics. 34(9): 666-681.

Vázquez-Ramos, J. (2016). Reparación del ADN: un asunto de vida... y de Premios Nobel. Educación Química. 27(2): 93-96.

Wang, M. Y., Zhao, R., Gao, L. J., Gao, X. F., Wang, D. P., and Cao, J. M. (2020). SARS-CoV-2: Structure, Biology, and Structure-Based Therapeutics Development. Frontiers in Cellular and Infection Microbiology. 10: 587269.

Wang, S., Yan, Z., Hänfling, B., Zheng, X., Wang, P., Fan, J., and Li, J. (2021). Methodology of fish eDNA and its applications in ecology and environment. Science of the Total Environment. 755: 142622.

Yamamoto, S., Masuda, R., Sato, Y., Sado, T., Araki, H., Kondoh, M., ..., and Miya, M. (2017). Environmental DNA metabarcoding reveals local fish communities in a species-rich coastal sea. Scientific Reports. 7(1): 1-12.

Yildiz, I., Açıkkalp, E., Caliskan, H., and Mori, K. (2019). Environmental pollution cost analyses of biodiesel and diesel fuels for a diesel engine. Journal of Environmental Management. 243: 218-226.

Yooseph, S., Andrews-Pfannkoch, C., Tenney, A., McQuaid, J., Williamson, S., Thiagarajan, M., ..., and Venter, J. C. (2013). A metagenomic framework for the study of airborne microbial communities. PLoS One. 8(12): e81862.

Zhu, H., Zhang, H., Xu, Y., Laššáková, S., Korabečná, M., and Neužil, P. (2020). PCR past, present and future. Biotechniques. 69(4): 317-325. 